\title{
GNREL
}

\section{Proceedings of the 2021 Airborne Wind Energy Workshop}

Jochem Weber, Melinda Marquis, Alexsandra Lemke, Aubryn Cooperman, Caroline Draxl, Anthony Lopez, Owen Roberts, and Matt Shields

National Renewable Energy Laboratory

NREL is a national laboratory of the U.S. Department of Energy Office of Energy Efficiency \& Renewable Energy Operated by the Alliance for Sustainable Energy, LLC

This report is available at no cost from the National Renewable Energy Laboratory (NREL) at www.nrel.gov/publications.
Technical Report

NREL/TP-5000-80017

July 2021 


\title{
GNREL
}

\section{Proceedings of the 2021 Airborne Wind Energy Workshop}

\author{
Jochem Weber, Melinda Marquis, Alexsandra Lemke, \\ Aubryn Cooperman, Caroline Draxl, Anthony Lopez, \\ Owen Roberts, and Matt Shields
}

National Renewable Energy Laboratory

\section{Suggested Citation}

Weber, Jochem, Melinda Marquis, Alexsandra Lemke, Aubryn Cooperman, Caroline Draxl, Anthony Lopez, Owen Roberts, and Matt Shields. 2021. Proceedings of the 2021 Airborne Wind Energy Workshop. Golden, CO: National Renewable Energy Laboratory. NREL/TP-5000-80017. https://www.nrel.gov/docs/fy21osti/80017.pdf.

NREL is a national laboratory of the U.S. Department of Energy Office of Energy Efficiency \& Renewable Energy Operated by the Alliance for Sustainable Energy, LLC

This report is available at no cost from the National Renewable Energy Laboratory (NREL) at www.nrel.gov/publications.

Contract No. DE-AC36-08GO28308
Technical Report NREL/TP-5000-80017 July 2021

National Renewable Energy Laboratory 15013 Denver West Parkway Golden, CO 80401 303-275-3000 • www.nrel.gov 


\section{NOTICE}

This work was authored by the National Renewable Energy Laboratory, operated by Alliance for Sustainable Energy, LLC, for the U.S. Department of Energy (DOE) under Contract No. DE-AC36-08GO28308. Funding provided by the U.S. Department of Energy Office of Energy Efficiency and Renewable Energy Wind Energy Technologies Office. The views expressed herein do not necessarily represent the views of the DOE or the U.S. Government.

This report is available at no cost from the National Renewable Energy Laboratory (NREL) at www.nrel.gov/publications.

U.S. Department of Energy (DOE) reports produced after 1991 and a growing number of pre-1991 documents are available free via www.OSTI.gov.

Cover Image by John Frenzl, NREL

NREL prints on paper that contains recycled content. 


\section{Acknowledgements}

The National Renewable Energy Laboratory (NREL) would like to acknowledge the representatives from leading national and international institutions who participated in this workshop. We are particularly indebted to the speakers for providing essential stimulus to make the workshop discussions productive. We would also like to thank the Airborne Wind Energy workshop committee members Ben Hallissy, Patrick Gilman, Bret Barker, Jochem Weber, Melinda Marquis, Alexsandra Lemke, Caroline Draxl, Jason Jonkman, Anthony Lopez, Owen Roberts, Matt Shields, Aubryn Cooperman, Rob Hammond, Michael Laurienti, and Eric Lantz. The workshop was sponsored by the U.S. Department of Energy's (DOE's) Wind Energy Technologies Office and virtually managed by NREL. Per DOE instructions, the workshop was conducted in compliance with the Information Quality Act. 


\section{Table of Contents}

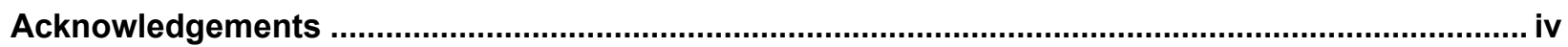

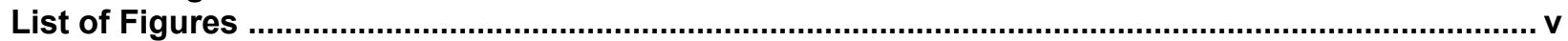

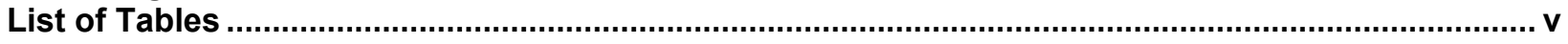

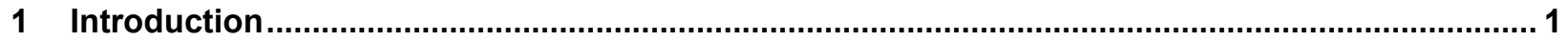

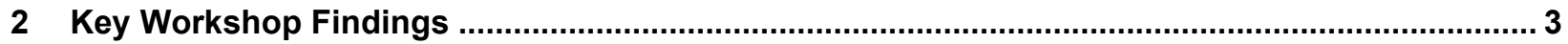

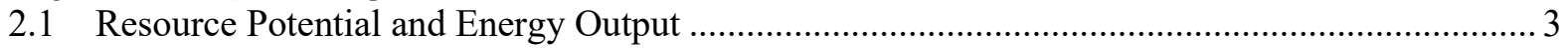

2.2 Technical Potential, Social and Environmental Impacts, and Permitting .................................. 3

2.3 Techno-Economic Analysis and Markets............................................................................... 3

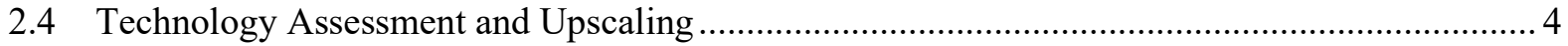

2.5 Research, Development, Demonstration, and Commercialization Needs ................................... 4

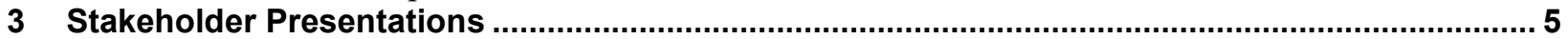

3.1 International Energy Agency Wind Topical Expert Meeting Overview | Planair......................... 5

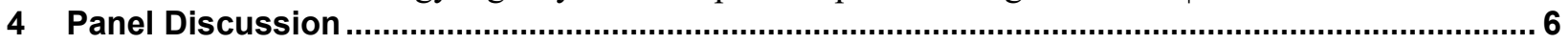

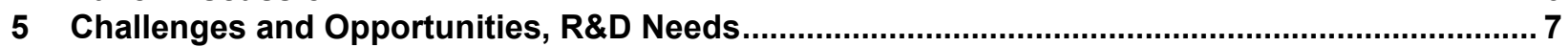

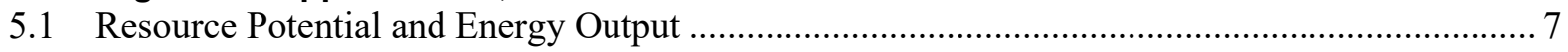

5.2 Technical Potential, Social and Environmental Impacts, and Permitting ................................ 9

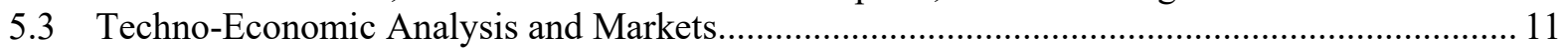

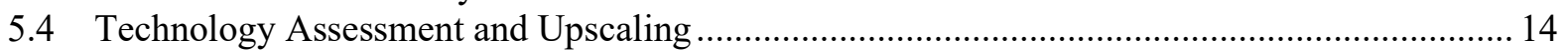

5.5 Research, Development, Demonstration, and Commercialization Needs ................................. 17

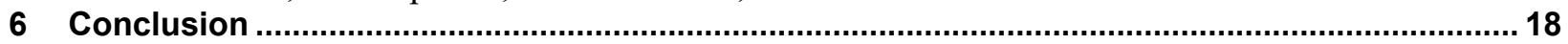

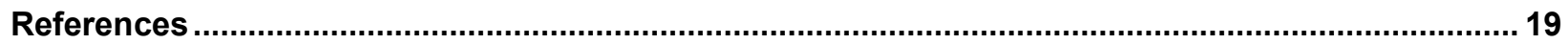

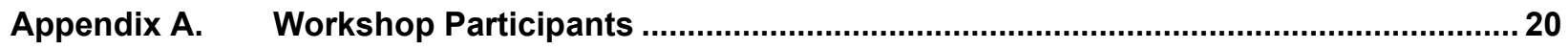

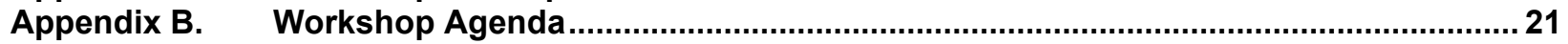

\section{List of Figures}

Figure 1. Initial target power curves for offshore, land-based, and distributed AWE systems for a projected commercial operation date in 2030. Note: These power curves were determined during the workshop to be unrepresentative of AWE performance. (note: $\mathrm{m} / \mathrm{s}$ is meters per second)....

Figure 2. Generic development trajectories over technology readiness and technology performance levels

\section{List of Tables}

Table 1. Spatial Siting Restrictions for AWE Technologies ........................................................ 9

Table 2. Estimated Wing and Flight Properties To Achieve Power Curves (Figure 1) Using Either a Rigid or Flexible Wing. Note: Some of these properties were determined during the workshop

to be unrepresentative of AWE performance.

Table A1. Participating Organizations in the Airborne Wind Energy Workshop................................220

Table B1. Agenda for the 2-Day Airborne Wind Energy Workshop .................................................... 21 


\section{Introduction}

Airborne wind energy (AWE) is the concept of producing electricity from a wind energy converter that is not supported by a tower; rather, AWE is supported by the wind alone - with the help of a tether connected to the ground. This concept has been researched intensively for at least four decades. In the most basic sense, AWE systems can be classified by the location of the generator: ground-gen systems have the generator on the ground, whereas flight-gen systems have the generator in the air with the converter. AWE may have the potential to provide low-cost electricity and address environmental impacts in a future energy system. The Energy Act of 2020 requests that the U.S. Department of Energy (DOE) deliver a "report on the potential for, and technical viability of, airborne wind energy systems to provide a significant source of energy in the United States, including a summary of research, development, demonstration, and commercialization needs, including an estimate of Federal funding requirements, to further examine and validate the technical and economic viability of airborne wind energy concepts over the 10-year period."

On March 2-3, 2021, the National Renewable Energy Laboratory (NREL) conducted a virtual workshop to evaluate the status, potential development, and technical viability of AWE systems as a source of energy in the United States. Stakeholder input provided at the workshop will contribute to the report to Congress. This report summarizes key workshop findings, current technology research and development (R\&D) activities in the United States, and opportunities and potential modes of collaboration and coordination for future technology R\&D activities.

The workshop focused on U.S. stakeholders in AWE, with approximately 100 experts and industry stakeholders from AWE technology developers, operators, engineering firms, consultants, government, national laboratories, and university researchers. The workshop began with an explanation from DOE's Wind Energy Technologies Office Technology Manager, Ben Hallissy, of the context and purpose of the workshop, including the report to Congress noted earlier. Next, brief introductions from workshop attendees explained their interest in AWE. Nicolas El Hayek of Planair summarized the proceedings from the AWE workshop held in September 2020 by the International Energy Agency (IEA) Wind Task 11. This was followed by a presentation by Roland Schmehl of the Delft University of Technology summarizing European AWE R\&D efforts. Chris Vermillion of North Carolina State University and Jason Jonkman of NREL presented an overview of U.S. R\&D efforts.

Next, five panelists discussed AWE markets, sizes of AWE systems, challenges, and opportunities. Panelists included: Cristina Archer, professor at the College of Earth, Ocean, and Environment and associate director at the Center for Research in Wind at the University of Delaware; Stephan Brabeck, chief technology officer at SkySails; Thierry Delahave, innovation and technology development lead at Saipem; Rob Creighton, founder and chief executive officer at WindLift; and David Schaefer, founder and chief executive officer at eWind Solutions.

The second day of the workshop began with a brief overview of five key topics that are crucial to enabling AWE in the United States. The following five topics set the stage for a robust discussion in breakout groups, wherein individuals offered their opinions on the potential opportunities for AWE in the United States: 
- Resource potential and energy output estimates the wind resource across the United States based on existing literature, over land and offshore, and at altitudes viable for AWE. In addition, this topic considers whether the AWE resource is overlapping or complementary to traditional wind, whether AWE would impact climate, and the estimated impact of wakes from AWE devices, which ultimately provide an estimated potential energy output.

- Technical potential, social and environmental impacts, and permitting explores the siting opportunities and challenges for AWE regarding social and environmental considerations. In addition, this topic explores the land-use requirements of different AWE technologies. These siting considerations led to the development of possible siting restrictions and land-use/ocean requirements. Assumptions developed in this area, combined with the resource potential and technology assessments, were used to estimate the overall technical potential of airborne wind energy systems, which is the quantity (megawatts $[\mathrm{MW}]$ ) and quality (megawatt-hours) of available wind resource for AWE development.

- Techno-economic analysis and markets considers the cost, logistics, and supply-chain considerations for a future, commercial-scale AWE system to identify market share opportunities. The relative benefits and drawbacks of a mature AWE system are compared with expected characteristics of traditional land-based and offshore wind systems for megawatt-scale machines and hundred-megawatt-scale projects.

- Technology assessment and upscaling addresses airborne wind energy technology systems across technology archetypes including concept of operations, design space, flight, structure, power conversion chain, takeoff, and landing and considers the state of the art as well as challenges and opportunities for upscaling the various systems to deliver significant energy.

- Research, development, demonstration, and commercialization needs addresses potential pathways for commercializing AWE, from demonstration to scaled concepts, for both land-based and offshore AWE applications. This topic covers the potential overlap of AWE and traditional wind turbines, and it identifies opportunities for developing AWE technologies in locations where traditional wind turbines may not apply. 


\section{Key Workshop Findings}

The following are key findings for the five topic areas addressed in the workshop:

\subsection{Resource Potential and Energy Output}

- Most AWE systems operate below 500 meters (m); therefore, the resource potential was considered for 0-500 $\mathrm{m}$ above ground level.

- NREL analyzed wind speed profiles at certain locations throughout the United States and found slightly negative, slightly positive, and mostly flat shear between $200 \mathrm{~m}$ and 500 $\mathrm{m}$.

- The wind resource at a 500-m height is not always greater than at $100 \mathrm{~m}$.

- Resource potential estimates must consider tether length and elevation angle because longer tether lengths tend to negate benefits of potentially faster winds at higher heights.

- Further research is needed regarding high-wind performance, high-wind controls, and safety related to gusts (how to dampen out instantaneous power surges) and modeling of turbulence.

\subsection{Technical Potential, Social and Environmental Impacts, and Permitting}

- Tether lengths are an important driver for setbacks and are likely to vary significantly between AWE designs and sites. Exploring a broad range of tether lengths was recommended.

- Avoiding populated areas was suggested; areas near transmission infrastructure were deemed high priority.

- Locations with existing solar and wind facilities could reduce the permitting process and demonstrate hybrid plant applications.

- Further research is needed to understand potential impacts of AWE on wildlife. The tethers have been raised as a concern for night-flying migratory birds.

\subsection{Techno-Economic Analysis and Markets}

- A 1-MW to 1.5-MW airborne wind energy system is an ambitious but feasible target for 2030.

- The lack of demonstrating a megawatt-scale AWE system to date contributes significantly to the uncertainty in future system sizes.

- Different proposed designs for multimegawatt AWE systems have significantly different tether lengths, ranging from $300 \mathrm{~m}$ to $1,400 \mathrm{~m}$ in length.

- System mass represents a significant variable in scaling to multimegawatt systems because increased mass leads to control challenges in maintaining tight flight circles, which influences siting and layout decisions.

- Further research is required to understand component and system mass-scaling relationships. 


\subsection{Technology Assessment and Upscaling}

- The sector needs to accumulate substantial operational time and gain related experience in flight operations, launching, landing, reliability, durability, performance, and gradual system improvement based on empirical data and experience.

- Increased testing efforts at reduced scales is a high priority.

- An experimental site for AWE technology R\&D would accelerate industry progress.

- Autonomous operation is critical to large-scale AWE deployment but has not yet been achieved.

\subsection{Research, Development, Demonstration, and Commercialization} Needs

- The public has little knowledge or understanding of the functional and economic attributes of AWE, which hinders investment and commercialization.

- Demonstration and commercialization of small-scale systems will be necessary to prove to utilities and investors that AWE is a viable energy producer.

- Small-scale systems must be commercialized to ensure an early revenue stream and demonstrate potential to investors and utilities.

- Public-sector support would not only assist AWE companies, but also lend credibility to this nascent industry.

- An experimental site is needed to assess the final levelized cost of energy (LCOE) of a commercialized product. 


\section{Stakeholder Presentations}

\subsection{International Energy Agency Wind Topical Expert Meeting Overview | Planair}

Nicolas El Hayek explained the IEA Wind Technology Collaboration Programme's (IEA TCP's) mission, organizational structure, and roles, and summarized the AWE online meeting that was hosted in September 2020. The IEA Wind TCP meeting included more than 90 participants and observers from 18 countries and 65 organizations that included 30 research institutes and universities, 12 original equipment manufacturers, and multiple policymakers. One meeting outcome was the proposal of a new IEA Wind task on AWE. Additionally, meeting participants identified the following topics for collaborative research:

- Resource potential and markets

- Social acceptance and environmental impacts, including noise, safety, and regulation architecture; and R\&D states, trends, and needs

- Development of joint reference models, tools, and metrics to enable the sector to develop.

\subsubsection{R\&D Overview European Union/Global| Delft University of Technology}

Roland Schmehl gave a presentation that addressed the AWE wind resource; performance modeling; system classification based on generator location, wing type, and flight operation; methods to optimize system design and operation of AWE systems; system control; flight dynamics, structural dynamics, aerodynamics and aeroelasticity of AWE systems; safety and reliability; cost-driven system designs; and environmental impacts and social acceptance.

\subsubsection{R\&D United States Overview | NREL and North Carolina State University}

Chris Vermillion gave a presentation that acknowledged notable commercial and academic achievements in AWE as well as several tools and reference models. He recommended that the IEA Airborne Wind task be used to establish a U.S. working group to work closely with the international community, standardize modeling tools, and build a fly-gen reference model based on the Makani system. Jason Jonkman discussed the NREL's KiteFAST simulation tool created to develop, verify, and support load analysis and structural design of the Makani system, before Makani shut down. 


\section{Panel Discussion}

Workshop organizers, Melinda Marquis and Jochem Weber of NREL, asked the invited panelists several questions to share information with all workshop attendees. The panelists ${ }^{1}$ included Cristina Archer, Stephan Brabeck, Thierry Delahave, Rob Creighton, and David Schaefer.

When asked what was envisioned for AWE in the next 10 years, one panelist talked about the possibility of many homes having an electric vehicle, solar panels, and an AWE kite. There was consideration of distributed applications for AWE in isolated locations, possibly replacing diesel generators on islands.

A question about a project to develop AWE for potential military uses elicited a response from another panelist about the need for consistent funding, a dedicated technical team, and metrics that make sense to both the customer and technical team. One panelist took this as an opportunity to thank the now-defunct Makani Technologies for sharing vast amounts of data and documentation accrued over years of developing an AWE system.

However, in the agricultural market, landowners in the Pacific Northwest that grow trees, fruits, and nuts find the possibility of additional income from AWE compelling because it requires little space on land.

One panelist spoke of partnerships with RWE Renewables to perform a pilot project on the feasibility of offshore AWE. The project would compare the performance of AWE flying at 800 $\mathrm{m}$ with a traditional offshore wind turbine. This team is aiming for reliability and a $70 \%$ capacity factor to achieve a high energy projection.

Also discussed were the needs to develop a supply chain for AWE technology. Some utilities that are interested in traditional offshore wind energy are now asking about AWE, indicating growing confidence in this technology.

When asked what the most important goals are, the panelists said reliability, AWE system certifications, financing, material development, academic support, survivability, and LCOE maturity. Near-term priorities noted were financing, certification, workforce development for composite technology, and cooperation among technology providers.

${ }^{1}$ Panelists' affiliations are provided in Section 1. 


\section{Challenges and Opportunities, R\&D Needs}

NREL performed a literature review on AWE to determine the state of the art, significant R\&D areas, and other information relevant to AWE's challenges, opportunities, and viability as a contributor to U.S. energy supply. NREL also conducted some simplified analyses in wind resource potential, technical potential, and techno-economics for AWE. The literature review, analyses, and breakout group discussions contributed to this section of the proceedings.

The workshop organizers developed a series of questions for participants to elicit individual feedback and gain an understanding of the potential opportunities for AWE in the United States. The following breakout groups were organized to address the group's theme, as indicated by the title, and to answer the related questions.

\subsection{Resource Potential and Energy Output}

Some literature identified the wind resource all the way up to the jet stream at 10 kilometers $(\mathrm{km})$. However, maximum altitudes at which most airborne devices operate are currently below $500 \mathrm{~m}$. Therefore, NREL focused its analysis on the airborne wind resource up to $500 \mathrm{~m}$. NREL also analyzed Weather Research and Forecasting simulations for 20 years, over Hawaii, the Pacific Northwest, the Atlantic Ocean, and a domain in the middle of the United States in the Great Plains. Depending on the area, NREL found that wind speeds are not always higher at 500 $\mathrm{m}$ than at $100 \mathrm{~m}$. NREL further analyzed wind speed profiles at certain locations that show slightly negative, slightly positive, and mostly flat shear between $200 \mathrm{~m}$ and $500 \mathrm{~m}$. NREL also looked at wind speed variability and found that the maximum wind speeds exhibit a seasonal cycle as well as a pronounced diurnal cycle. Lastly, NREL used generic power curves, introduced by Matt Shields, to calculate annual energy production estimates and gross capacity factor at select locations. This initial analysis showed lower-than-expected gross capacity factors. Much higher capacity factors may be expected because of flight control options.

\section{How are the winds at higher altitudes characterized over the United States? Are they overlapping or complementary with traditional wind? What is the spatial distribution of the wind resource, and its temporal variability?}

- Former Makani employees suggested that NREL's U.S. resource assessment is consistent with what the company had found previously.

- The relevant wind resource is considered by most workshop participants to be below 500 $\mathrm{m}$, though at least one participant is pursuing altitudes close to $1,000 \mathrm{~m}$. The reason for this is that discussions about the wind resource need to go hand in hand with discussions about tether length and elevation angle. Flying at higher altitudes would require longer tethers and elevation angles, both of which tend to negate potential gains from higher heights.

- Pursuing higher wind speeds at different heights does not make much sense without a high wind shear. Future analyses should account for realistic shear. Chasing higher wind speeds at greater heights might not be worth it; however, some stakeholders in Europe have been successfully flying AWE systems at higher altitudes.

- Wind resource assessment methods need to be established for the altitudes relevant for AWE operation to develop reliable estimates on technical and market potential. 
- Apart from the effects of wind shear, the vertical extension for energy extraction space and related wind energy flux may increase the viable energy extraction per unit land area.

- Increased potential can be seen less in height than in additional space where devices can be deployed; for example, farther out offshore. With a similar energy production per $\mathrm{km}^{2}$, AWE production could be cheaper in those areas.

- Even if AWE and traditional wind energy tap into the same resource, other factors, such as system design, location, transportation, costs, and service, should also be considered. The value proposition of AWE is not limited to the compound metric of LCOE. Other characteristics of both AWE and traditional wind should be considered. For instance, the simplicity and relatively low cost required to transport AWE devices is an advantage over traditional wind turbines. At least initially, most cost advantages for AWE will be from early-adopter markets with limited capacity for traditional wind turbines.

- Wake losses are expected to be minimal, but more research is needed, especially before large field deployments are planned. Site compactness is hard to determine because of the difficulty of controlling the kites.

\section{How much more energy can be extracted due to higher winds at altitudes viable for $A W E$,} compared to traditional wind?

- Discussions about the wind resource need to consider tether length and elevation angle because longer tethers and larger angles tend to negate gains from higher heights.

- Fundamentally increased resource potential can be achieved through positive wind shear and/or through extending into larger areas with wind energy flux.

\section{What are the key capability gaps to complete the research and development path?}

- Tests are needed regarding high-wind performance, high-wind controls, and safety related to gusts (how to dampen out instantaneous power surges). Makani's report addressed several questions in this area. Exiting high winds with Makani's design could take tens of seconds because of the mechanics of cornering; landing takes a similar amount of time but requires power consumption.

- Turbulence and gusts can represent problems for some AWE system controls.

- In relation to design load, the following questions were posed: what are the atmospheric conditions a system needs to be designed for? Is it the 50-year gusts? Which phenomena can be avoided? Designing for extreme loads is still an open question.

- Modeling turbulence more accurately is important to system-control design.

- AWE siting needs more detailed research on possible impacts of wakes; however, this is not considered to be among the highest-priority research. 


\subsection{Technical Potential, Social and Environmental Impacts, and Permitting}

This topic explored the challenges and opportunities regarding social and environmental siting considerations for AWE. Prior to the workshop, NREL conducted interviews with leading experts in wind and wildlife, social dynamics, and permitting (the U.S. Department of Defense [DOD] Clearinghouse and the North American Aerospace Defense Command [NORAD]). Based on the interviews and literature review, NREL created a set of spatial constraints. The high-level takeaways from the interviews, as well as the spatial constraints developed by NREL, were presented and discussed with workshop attendees. In addition, as identified in Table 1, the spatial constraints were used in combination with the power curves and capacity density developed in the techno-economic and market analysis group to develop an initial estimate of technical potential for AWE - effectively, the quantity (megawatts) and quality (megawatt-hours) of available wind resource for AWE development. Results were presented and discussed. Below are highlights and main takeaways from the workshop discussions.

Table 1. Spatial Siting Restrictions for AWE Technologies

\begin{tabular}{|c|c|}
\hline Siting Exclusion Category & Exclusion Details \\
\hline \multicolumn{2}{|l|}{ Infrastructure } \\
\hline $\begin{array}{l}\text { Setbacks to transmission right of way, railroads, roads, building } \\
\text { structures }\end{array}$ & $\begin{array}{l}\text { Setback }=1.5 x \text { tether length }(1,500 \mathrm{~m} \text {, } \\
750 \mathrm{~m})\end{array}$ \\
\hline Urban areas and airports & Excluded, $10-\mathrm{km}$ setback \\
\hline Radar & $\begin{array}{l}\text { 4-km NEXRAD, 9-km short- and long- } \\
\text { range radar }\end{array}$ \\
\hline \multicolumn{2}{|l|}{ Regulatory } \\
\hline Protected public lands and conservation easements & Excluded \\
\hline \multicolumn{2}{|l|}{ Physical } \\
\hline Slope $>25 \%$ & Excluded \\
\hline Mountainous land forms and high $(>9,000$-foot) elevation & Excluded \\
\hline Water and wetlands (with a $305-\mathrm{m}$ buffer) & Excluded \\
\hline
\end{tabular}

Which setback distances are most appropriate from a social and technical perspective (e.g., setbacks from residences, transmission lines, radar towers, airports, roads, and viewshed considerations)?

- Tether lengths drive possible setbacks from civil infrastructure and buildings. NREL evaluated 1.5x-tether-length setbacks for a 500-m and 1,000-m tether. While some operators expect to use these tether lengths, others were planning to operate with $200-\mathrm{m}$ to 500-m tether lengths. Further, at least one attendee was experimenting with tether lengths exceeding $2,700 \mathrm{~m}$. Thus, it was recommended to explore a broader range of tether lengths and evaluate the land-availability impacts for AWE. Similarly, it was suggested that kite design is likely to be custom to siting conditions; thus, a siteoptimized approach would better illuminate the technical potential. 
- It was recommended that a study sweeping through the tether length and associated setbacks would be a good addition to the literature.

- Road setbacks were perceived as potentially being too restrictive and perhaps could delineate varying setbacks for different types of roads and traffic counts.

- Radar setbacks are not a firm exclusion but do require coordination with the DOD Clearinghouse and/or NORAD.

- NREL applied a simple 10-km proximity limit to airports. It was recommended that exclusions should delineate approach corridors and consider kite flight altitude.

- Tribal lands were perceived as a possible exclusion for AWE because of permitting difficulties.

- Viewshed was not a high concern to workshop participants. One reason is that AWE could be grounded during the day and operated at night to reduce visual disturbance. Also, AWE has a perceived low-visibility profile than traditional wind turbine technology.

- There was open debate whether AWE would be allowed to operate over populated locations. However, it was agreed that more testing is needed to ensure safety.

- Based on Makani's experience, the Federal Aviation Administration considers AWE an obstruction, not an aircraft.

\section{What are the technical ocean-depth limits of $A W E$ ?}

- No limits were identified.

Which locations might preclude development or prove difficult for permitting because of sensitive ecology and wildlife (e.g., federal lands, bird migration routes, protected lands) and what research might be needed to assess potential impacts?

- There is a lot of uncertainty on the wildlife impacts of AWE. Some suggest it would be minimal given AWE's characteristics (i.e., soft wings, tethers, high-altitude operation). In addition, the ability of AWE to be grounded during bird migration is seen as an advantage. However, all workshop participants agreed that further research is needed. It was noted that an environmental assessment and impacts-to-birds study is ongoing in Norway and will be published by Airborne Wind Europe, the association of the European AWE industry.

- Deployments in forested areas were discussed. Tree clearing would be required, although the exact perimeter was not delineated. In addition, canopy height was discussed as a potential siting issue; however, exact heights were not determined.

Are there locations that could be prioritized for $A W E$ deployment (e.g., near existing wind or solar power plants or in proximity to existing transmission infrastructure)?

- Avoiding populated areas was suggested; areas near transmission infrastructure were deemed high priority.

- Locations with existing solar and wind facilities could reduce the permitting process and demonstrate hybrid plant applications.

- DOD bases present opportunities for testing — specifically, Fort Bragg and Fort Lejeune.

- Quantifying and identifying nonsynchronous siting locations with traditional wind technology could illuminate siting opportunities for AWE. 


\subsection{Techno-Economic Analysis and Markets}

This topic considers cost, logistics, supply chain, and market share opportunities for a future commercial-scale AWE system. The goal is to compare the relative benefits and drawbacks of a mature AWE system with expected characteristics of traditional land-based, offshore, and distributed wind energy systems for megawatt-scale machines and hundred-megawatt-scale projects for a commercial operation date in the 2030s. Prior to the workshop, NREL developed a set of candidate assumptions representative of potential full-scale AWE systems. Workshop participants were asked to provide feedback to refine and improve the representativeness of the commercial-scale AWE systems.

The initial rated-power targets for commercial AWE systems were set equal to projected traditional wind energy systems in 2030, based on the NREL Annual Technology Baseline "Moderate" scenario (NREL 2020). Power ratings were set to 15-MW offshore, 5-MW landbased, and $1 \mathrm{MW}$ for distributed (off-grid) systems. A representative power curve was created for each topology (Figure 1), with related assumptions around wing area, aerodynamic properties, losses, flight path, and ground clearance to achieve such a power curve (Table 2). Geometric parameters of the AWE systems were used to estimate capacity density and spatial setbacks from existing infrastructure. The opportunity for AWE to be cost competitive with traditional wind systems at a commercial scale, as well as the opportunity to serve niche markets, was discussed.

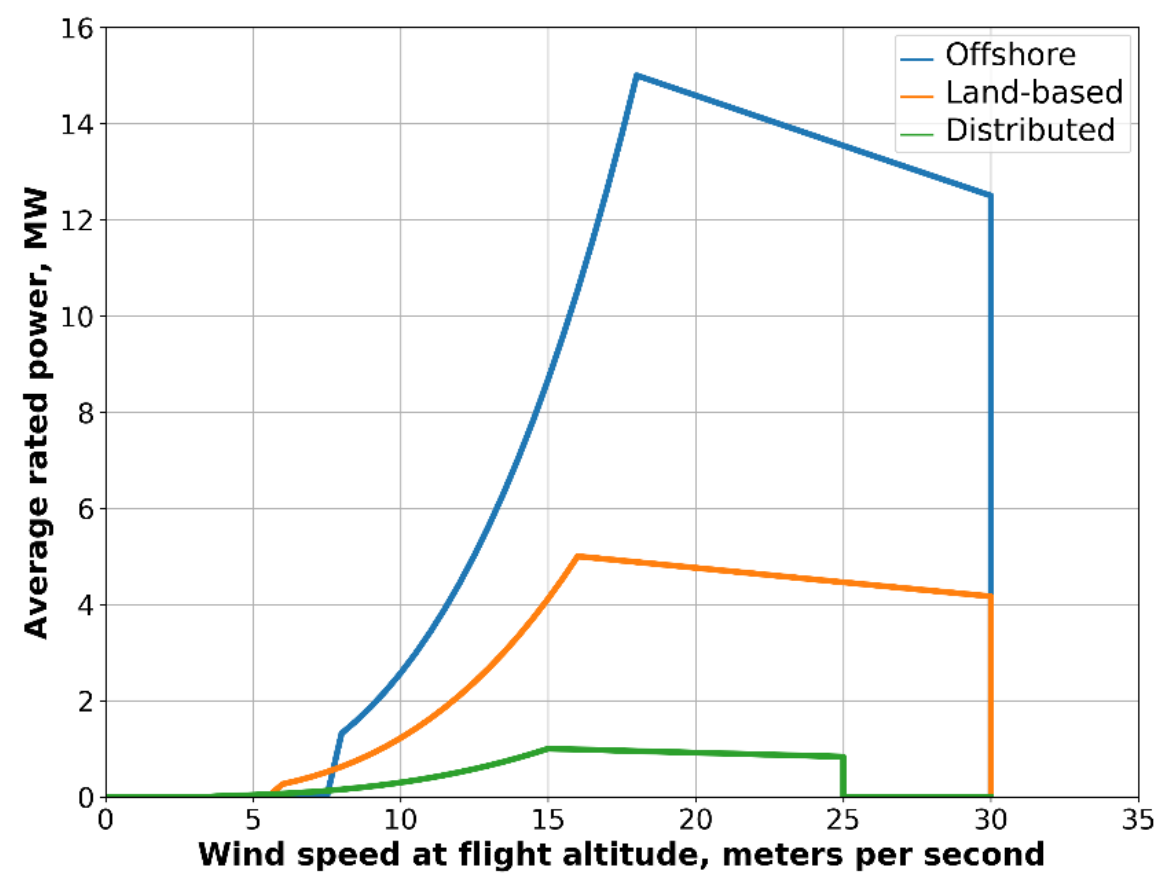

Figure 1. Initial target power curves for offshore, land-based, and distributed AWE systems for a projected commercial operation date in 2030 . Note: These power curves were determined during the workshop to be unrepresentative of AWE performance.

Discussion during the workshop focused on whether these are reasonable targets for the development of airborne wind energy in the next decade and if the shape of the power curves is appropriate. 
Table 2. Estimated Wing and Flight Properties To Achieve Power Curves (Figure 1) Using Either a Rigid or Flexible Wing. Note: Some of these properties were determined during the workshop to be unrepresentative of AWE performance.

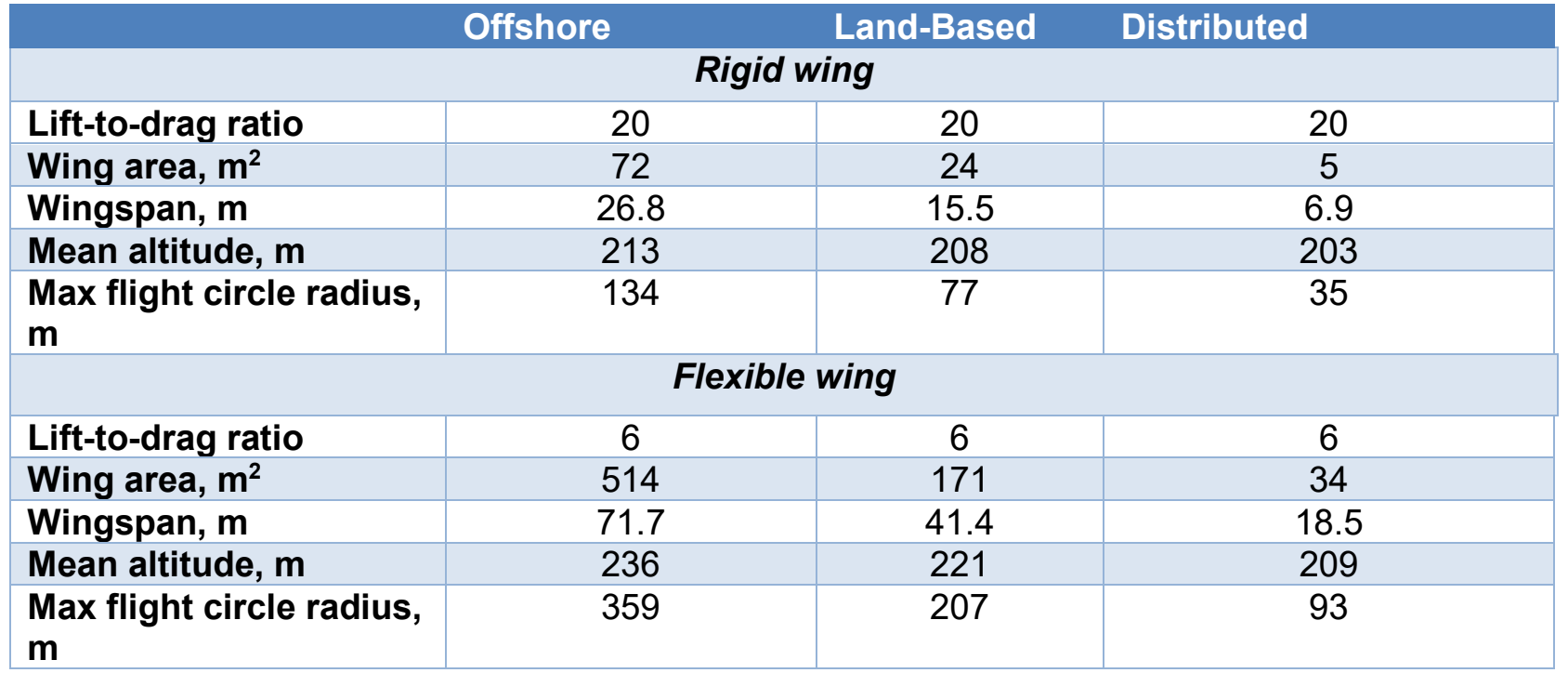

Are the power curves in Figure 1 realistic and representative of future technologies? Consider rated power, cut-in and cut-out wind speeds, and curve shapes.

- Participants agreed that the target of a 15-MW offshore wind system was too high. There was no suggestion that a $15-\mathrm{MW}$ system would be feasible by 2030 . One participant indicated that scaling up to $10 \mathrm{MW}$ to $15 \mathrm{MW}$ would require improvements in the performance of composite materials. There was disagreement about whether a 5-MW system is feasible by 2030, with some participants targeting production of a 5-MW system in 2030 and others expressing the belief that $1 \mathrm{MW}$ to $1.5 \mathrm{MW}$ is an ambitious but feasible target for that time frame. A 1-MW system is yet to be demonstrated. One participant described $1 \mathrm{MW}$ as the optimal system size for land-based AWE systems.

- There was general agreement that the power curves should be shifted down (i.e., regulating power at lower wind speeds). Wind speeds between 7 meters per second $(\mathrm{m} / \mathrm{s})$ and $12 \mathrm{~m} / \mathrm{s}$ were suggested as appropriate for reaching rated power. Participants expect individual AWE systems to be designed to reach rated power at different speeds depending on the wind resource at the device location. It was also recommended to lower the cut-out wind speed by $10 \mathrm{~m} / \mathrm{s}$ based on economic considerations. Wind speeds above $20 \mathrm{~m} / \mathrm{s}$ are relatively infrequent and impose high loads and control challenges for keeping AWE systems aloft, so the costs of operating in these conditions are expected to outweigh the power production benefits.

- Several participants commented that a linear relationship between wind speed and power output would be more appropriate than a cubic relationship for the region between cut-in and rated power (Region 2), or possibly in the upper half of this region. Tether strength limits were described as the primary driver for the curve shape in this region while kite air speed and controllability were also cited as factors. 
What physical kite parameters-lift-to-drag ratio, wing area, flight circle, tether lengthwould you need to achieve the power curves in Figure 1?

- Participants agreed that the wing sizing in Table 2 is too small by up to an order of magnitude. The values in the table were derived from Loyd's estimate of maximum power production (Loyd 1980). Participants stated that Loyd's formula overpredicts power production when compared to flight tests because it fails to capture important physical system dynamics by neglecting the effects of mass. As system sizes become larger, mass becomes more significant based on simple scaling relationships (the "squarecube law") and one participant speculated that mass could dictate an upper limit on the size of AWE systems. Mass also affects the minimum cut-in wind speed for AWE devices by setting a minimum lift required to keep the device airborne.

- In considering the lift-to-drag ratio, participants pointed out that it is important to specify whether the drag coefficient refers only to the airfoil or to the entire system, including the tether (and rotors in the case of a fly-gen system). Obtaining a lift-to-drag ratio of 20 requires a high-aspect-ratio wing. One participant suggested that a reasonable limit on the maximum wingspan of a soft kite would be $70 \mathrm{~m}$.

- Flight paths are affected by kite size and weight. A minimum turning radius of 4-5 wingspans was identified as a reasonable limit, and a participant commented that the kite mass limits the ability to turn sharply. Flight-path errors of 1-2 wingspans have been observed in flight tests.

- Several participants described reasons to limit operating altitudes, including losses because of tether drag and weight, and "cosine" losses related to the elevation angle. Different values were proposed as target tether lengths for a 5-MW system, ranging from $300 \mathrm{~m}$ to $1,400 \mathrm{~m}$. A participant also pointed out that other concepts may be demonstrated by 2030 that would change the effect of tether length on performance; for example, a single tether with multiple kites.

- For AWE systems with ground-based generators, the reel-out and reel-in cycle creates large swings in power output. Participants recommended that NREL discuss the impact of power cycling on the power curve. Examples of the impact of reel-out cycles on component sizing included extending the tether length by $40 \%$ from its minimum value and oversizing the generator by a factor of 2.5 .

\section{What might a commercial-scale land-based or offshore AWE plant look like? What are the installation and operational logistics required to construct and maintain such a plant?}

- Participants discussed several factors that impact AWE-system spacing and capacity density. Spacing of $250 \mathrm{~m}$ to $330 \mathrm{~m}$ between 2-MW kites was suggested by one participant. Examples of setbacks to existing structures included fixed buffers of $50 \mathrm{~m}$ to $400 \mathrm{~m}$ above the tether length instead of a $50 \%$ factor.

- Spacing will be partially determined by requirements for emergency procedures for landing a system. 
What is the opportunity space for cost reduction relative to a traditional wind project of equal size? Does $A W E$ offer additional value opportunities in addition to cost savings relative to traditional wind, such as reduced reliance on expensive and scarce cranes or installation vessels? Is $A W E$ better suited to commercial-scale (hundred-megawatt) deployment or specific markets? Under what conditions would a developer select an airborne turbine instead of a traditional turbine?

- Planning to site AWE where traditional wind is not deployed (at places with lower wind speeds) may provide value to the power system. AWE systems have a competitive advantage because of lower capital costs.

- Currently looking at distributed wind versus on-grid AWE systems; offshore wind will require a lot more validation work.

- Obtaining a high-capacity factor is key to applications, including grid support and hydrogen generation.

- There may be potential for cost reduction compared with off-the-shelf components from aviation, but minimizing weight is still an important driver that could limit cost reductions.

- Lower balance-of-system requirements offshore will provide advantages to AWE systems compared with traditional wind and will drive AWE systems to the largest feasible device sizes.

What are the key risks associated with AWE technology, permitting, and deployment? Can these risks be mitigated by future $R \& D$ investment, stakeholder outreach, or other methods?

- The tether system needs to incorporate redundancy for safety. AWE systems operators will need to consider emergency landing contingencies.

- Materials used in AWE systems may require large energy inputs or have high carbon footprints (e.g., carbon fiber and Dyneema rope).

\subsection{Technology Assessment and Upscaling}

This topic aimed to explore the key challenges and opportunities of AWE technology systems across technology archetypes, including concept of operations, design space, flight, structure, power conversion chain, takeoff, landing - and more. It also considered the state of the art, challenges, and opportunities for upscaling the various systems to deliver significant energy contributions as well as related R\&D needs. The technology development process and status were discussed in context with the functional requirements and the progress metrics of commercial technology readiness (Figure 2) and techno-economic performance toward reaching market entry. Workshop participants also considered the methods and tools needed to assess research and technology development needs, capabilities, and infrastructure (hard and soft) to complete the technology development toward deployment in a diverse range of markets. 


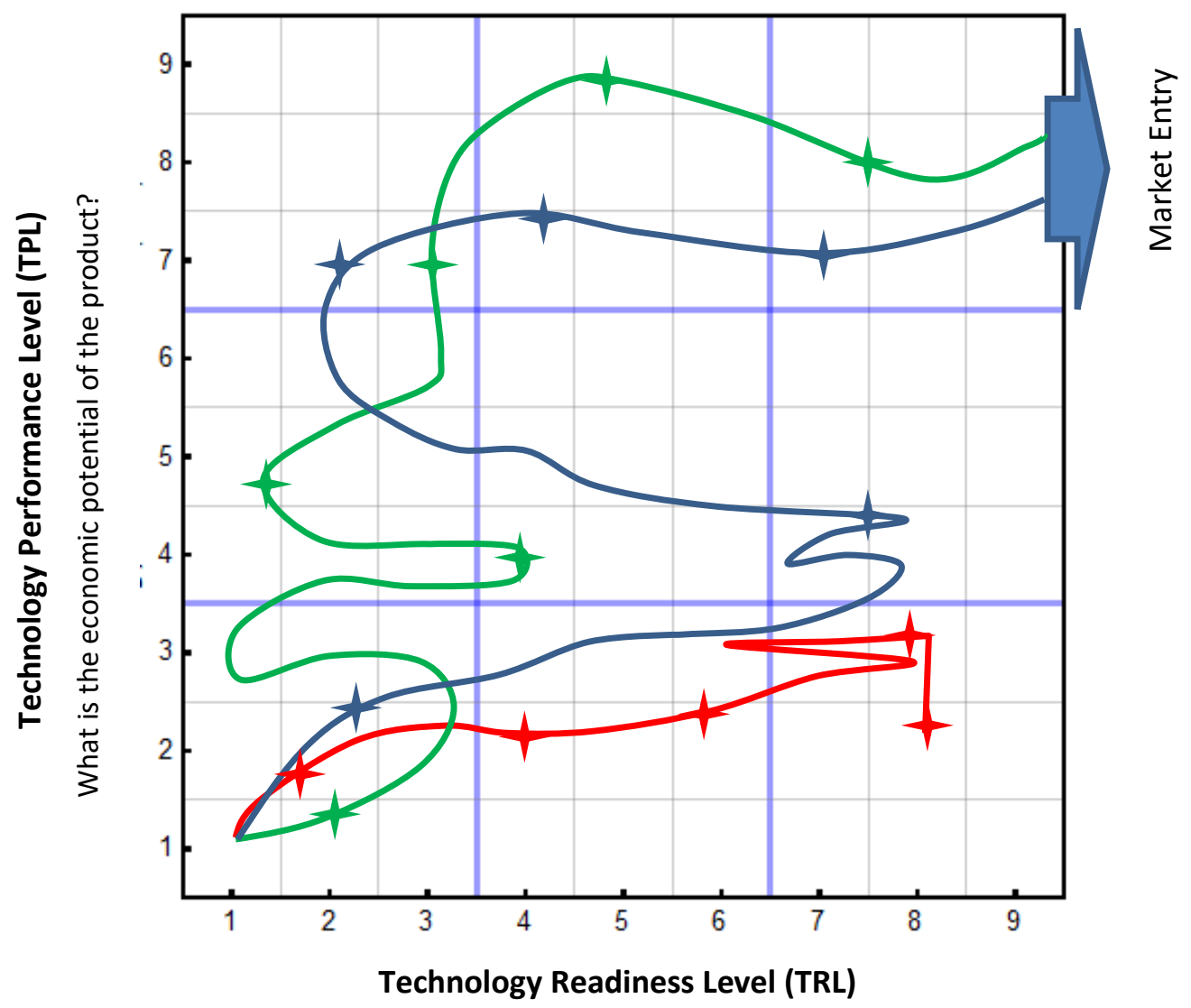

How close is the technology to becoming a product?

Figure 2. Generic development trajectories over technology readiness and technology performance levels

What are your targeted market entry requirements and the critical technology development challenges-dependent on the different application and/or market segments?

- Depending on the technology archetype (e.g., fly-gen, ground-gen, other) and the targeted market, the technology development priorities are very different. For instance, earlyadopter markets in microgrids and industrial settings are designed around an acceptable and manageable level of operation, automation, and manual operation and maintenance, whereas offshore wind energy installations require very high degrees of automation during all states and modes with extensive reliability.

What are the key performance indicators to assess the technology development status? What is the technology development status regarding readiness, performance, and reliability?

- The current technology development status across the sector varies significantly from low to medium-high technology readiness (e.g., from early and small-scale model flight testing for short flight durations to the onset of the first pilot projects).

- Some technology developers are entering pilot projects based on first commercial technology sales; however, the systems are not operated under pure commercial operational conditions. 
- The focus of the technology development differs considerably, depending on the technology archetype and targeted markets, and the technology readiness levels (TRLs) differ widely across the sector.

- The overall system TRL may differ significantly across the different operational modes (e.g., launch, flight, generation, landing) and functions as well as across subsystems and components.

- Some enabling subsystems and/or components developed in different and mature technology domains that are utilized in AWE technology development are at high TRLs or are fully commercial, such as sensors or power conversion chain subsystems.

\section{What are the key capability gaps to complete the research and development path toward market entry — dependent on the different application and/or market segments?}

- A systematic approach is required for identifying system requirements dependent on markets, applications, and systems engineering approaches.

- The sector needs to accumulate substantial operational time and gain related experience with respect to flight operations, launch, landing, reliability, durability, and gradual system improvement based on empirical data and experience.

- Subsystem and component testing is considered of high importance to retire risk from system testing and operations.

- Increased testing efforts at a small problem-relevant scale, in combination with advanced simulation tools, is regarded as one of the highest priorities to further technology development.

- Simulation-tool development for design, optimization, and exploration and access to related computational infrastructure is very important.

- Common points of reference are highly important. For example, a reference system of the key AWE technology archetypes, and agreed-upon methods to measure and display technology performance, would be helpful.

- Different schemes to foster substantial operational time were desired across the sector (e.g., prize competitions, accelerators, fly-offs, and so on).

- Autonomous operation is critical to large-scale AWE deployment.

- An experimental site and center for technology development and expertise would help the sector advance.

\section{Related Takeaways}

- Technology scaling can take different forms, depending on the technology archetype and market. Fly-gen and rigid-wing-type systems scaling constraints appear to be driven by mass and structural design. Ground-gen and soft-wing type systems may suffer less from flight-production-operations scaling constraints but may experience durability and handling constraints. Apart from scaling of single units, the scaling by number and interconnection is proposed with twin-kite, multikite, and network systems. Scaling with respect to installed capacity or energy production per land/surface area may be achieved by combining or staggering kites at multiple flight levels.

- Even though the variety of system design approaches is plentiful, the concept solutions and design space have not been sufficiently explored. Improvements over the state of the art are possible. 


\subsection{Research, Development, Demonstration, and Commercialization Needs}

This topic addressed potential pathways for commercializing AWE from demonstration to scaled concepts, for both land-based and offshore wind applications. Workshop participants discussed the potential overlap of AWE with traditional wind turbines and identified opportunities for developing AWE technologies where deployment of traditional wind turbines may not be applicable. These discussions should refine the concepts, scale, and development pathways of land-based and offshore AWE. We concluded with recommendations for future research, potential approaches for technology development, demonstration, and commercialization approaches for AWE.

What are the highest priorities and next steps for commercializing of AWE technologies from the standpoint of technology developers and project developers?

- AWE would benefit from more visibility with the public through small-scale demonstrations, resulting in increased adoption and investments to improve commercialization pathways.

\section{What $R \& D$ investments are needed to commercialize AWE technologies?}

- A test site is needed to truly assess the final LCOE of a commercialized product. This will also lower time spent seeking regulatory approval for tests.

- Public-sector support would not only benefit AWE companies but would also increase the technology's credibility.

- Demonstrating and commercializing smaller-scale systems will be necessary to prove the technology and its viability to utilities and investors.

What are the scales, controls, design codes, social acceptance, airspace, scaled device demonstrations, investment, and market opportunity topics that are key?

- While smaller-scale systems may not be the intended final market, they must be commercialized to ensure an early revenue stream and show product potential to investors and utilities.

- AWE's LCOE will have to be lower than traditional wind's LCOE, or display additional value propositions, to attract developers to a new technology. 


\section{Conclusion}

Bringing together U.S. stakeholders in AWE was valuable. A long time has occurred since such an event was held in the United States. Most participants agreed that AWE has the potential to contribute a significant amount of electricity to the power grid, particularly in certain applications and markets. One or more technology centers with theoretical and experimental R\&D capabilities, including facilities and an experimental site, would greatly catalyze R\&D efforts and the sector. 


\section{References}

Loyd, M. L. 1980. “Crosswind Kite Power.” J. Energy. Vol. 4, pp. 106-111.

http://edge.rit.edu/edge/P15462/public/CAD/crosswind kite.pdf.

National Renewable Energy Laboratory. 2020. “Annual Technology Baseline.” Golden, CO:

National Renewable Energy Laboratory. https://atb.nrel.gov/. 


\section{Appendix A. Workshop Participants}

Table A1. Participating Organizations in the Airborne Wind Energy Workshop

\begin{tabular}{|c|c|}
\hline AirLoom Energy & Purdue University \\
\hline Ampyx Power & RDT Engineers \\
\hline Arkansas State University Campus Queretaro & Rochester Institute of Technology \\
\hline A-Z Chuteworks LLC & RRD Engineering, LLC \\
\hline Bmapper & Saipem \\
\hline Boston Government Services & Siemens Gamesa \\
\hline Brigham Young University & Shiv Nadar University \\
\hline Bureau of Ocean Energy Management & SkySails Power \\
\hline DNV GL & Southeastern Wind Coalition \\
\hline Enerkite & Toyota \\
\hline EWind Solutions, Inc. & Delft University of Technology \\
\hline Hoodtech & U.S. Marine Corps \\
\hline kiteKRAFT Inc. & University of California, Santa Barbara \\
\hline Kitemill & University of Delaware \\
\hline Kitepower & University of Maryland \\
\hline KitGen & University of Victoria \\
\hline kPower & University of Washington \\
\hline Makani (former) & Unmanned Systems Research Institute-Oklahoma State University \\
\hline Mowinckel & U.S. Department of Energy \\
\hline National Aeronautics and Space Administration & Virginia Polytechnic Institute and State University \\
\hline National Renewable Energy Laboratory & Wind Energy Technologies Office, U.S. Department of Energy \\
\hline North American Aerospace Defense Command & WindForS wind energy research cluster \\
\hline North Carolina State University & WindLift LLC \\
\hline north KB & Worcester Polytechnic Institute \\
\hline \multicolumn{2}{|l|}{ Oregon State University } \\
\hline Planair SA & \\
\hline
\end{tabular}




\section{Appendix B. Workshop Agenda}

Table B1. Agenda for the 2-Day Airborne Wind Energy Workshop

\begin{tabular}{|c|c|}
\hline \multicolumn{2}{|c|}{$\begin{array}{c}\text { Tuesday, March 2, } 2021 \\
\text { Stakeholder Presentations, Research and Development (R\&D) Activities, and Technology } \\
\text { Status }\end{array}$} \\
\hline 8:00 a.m. & Welcome, TEAMS Best Practices, and Logistics \\
\hline 8:05 a.m. & $\begin{array}{l}\text { Opening Remarks and Goals of the Workshop } \\
\text { Ben Hallissy | U.S. Department of Energy's Wind Energy Technologies Office }\end{array}$ \\
\hline 8:10 a.m. & $\begin{array}{l}\text { Introduction, Purpose, and Goals of the Workshop } \\
\text { Jochem Weber and Melinda Marquis | National Renewable Energy Laboratory } \\
\text { (NREL) }\end{array}$ \\
\hline 8:20 a.m. & $\begin{array}{l}\text { Attendee Introduction } \\
\text { Each participant may volunteer to provide information on any of the following: } \\
\text { 1) What is your name, team, and role in airborne wind energy (AWE)? } \\
\text { 2) What is your technology or research area? } \\
\text { 3) What are the goals you are trying to achieve in AWE? } \\
\text { 4) What is needed for your organization to be successful? }\end{array}$ \\
\hline 9:10 a.m. & Break \\
\hline 9:30 a.m. & $\begin{array}{l}\text { Presentations and Q\&A } \\
\text { - International Energy Agency Wind Topical Expert Meeting Overview | Planair } \\
\text { - } \quad \text { R\&D Overview EU/Global | Delft University of Technology } \\
\text { - } \quad \text { R\&D Overview United States | NREL and North Carolina State University }\end{array}$ \\
\hline 10:30 a.m. & $\begin{array}{l}\text { Facilitated Panel Discussion } \\
\text { Facilitators: Jochem Weber and Melinda Marquis | NREL } \\
\text { Panelists: } \\
\text { - } \quad \text { Thierry Delahaye | Saipem } \\
\text { - Stephan Brabeck | SkySails Power } \\
\text { - } \quad \text { Christina Archer | University of Delaware } \\
\text { - David B. Schaefer | eWindSolutions }\end{array}$ \\
\hline $11: 45$ a.m. & $\begin{array}{l}\text { Wrap-Up and Introduce Day } 2 \text { Activities } \\
\text { Melinda Marquis | NREL }\end{array}$ \\
\hline 12:00 p.m. & Adjourn \\
\hline
\end{tabular}




\begin{tabular}{|c|c|}
\hline & $\begin{array}{c}\text { Wednesday, March 3, } 2021 \\
\text { Challenges and Opportunities, R\&D Needs }\end{array}$ \\
\hline 8:00 a.m. & Welcome and Recap of Day 1 \\
\hline 8:05 a.m. & $\begin{array}{l}\text { Purpose, Goals, and Breakout Topics } \\
\text { - Resource potential and energy output } \\
\text { - Technical potential, social and environmental impacts, and permitting } \\
\text { - Techno-economic analysis and markets } \\
\text { - Technology assessment and upscaling } \\
\text { - Demonstration and commercialization needs }\end{array}$ \\
\hline $8: 25$ a.m. & Breakout 1 - Small Group Discussion \\
\hline $9: 30$ a.m. & Break \\
\hline 9:50 a.m. & Breakout 2 - Small Group Discussion \\
\hline 11:05 a.m. & Break \\
\hline $11: 20$ a.m. & Breakout Group Report Outs and Q\&A \\
\hline 12:45 p.m. & Next Steps, Closing Remarks, Adjourn \\
\hline
\end{tabular}

